\title{
HAKEMSIZ MAKALELER
}

\section{Alman Ceza Yargılamasında Delillerin Kullanılması Yasağı - Anlamı, İşlevi ve Şartları}

\author{
Alman Ceza Yargılamasında Delillerin Kullanılması Yasağı - Anlamı, \\ İşlevi ve Şartları
}

\section{Joachim KRETSCHMER ${ }^{*}$ H. Özden ÖZKAYA-FERENDECI ${ }^{* *}$}

Örnek (BGHSt, 34, 362): Bir şüpheli cinayet işlediği şüphesi ile tutuklanıp gözaltına alınmıştır. Şüpheli, kanunun ona tanıdığı susma hakkından faydalanarak, konuya ilişkin hiçbir ifade vermemiştir. Bunun üzerine şüphelinin yanına gözaltında tutulan başka bir şüpheli konuldu. İkinci şüpheli, yargı organlarına yardım etmeye hazırdı ve ilk şüpheliye baskı uygulayarak, kaçma planları yaptığını ifade ederek kaçınca da başka suçlar da işleriz diye ilk şüphelinin aklına girerek, ilk şüphelinin ağzından laf aldı. Bunun üzerine ilk şüpheli, ikinci şüpheliye karşı işlediği cinayetten söz etti ve ikinci şüpheli de bunu doğrudan savcılığa anlattı.

Devlet, ceza adaleti bakımından bu şekilde davranabilir mi? Ne diyorsunuz? Hukuki şüpheleriniz var mi?

Ceza yargılamasında delil kullanma / değerlendirme yasağı nedir? Bu soruya çok basit ifade ile cevap vermek gerekirse, ceza yargilamasında bir delilin veya bir delil incelemesi sonucu elden edilen sonucun - yargılama hukukuna aykırı şekilde veya insan haklarını ihlal ederek elde edilmiş olması rağmen - kullanılabilirliğinin tartışılmasıdır. Bu şekilde elde edilmiş ve bundan dolayı "lekeli, yani temiz olmayan" deliller ve delil sonuçları ceza yargılamasında değerlendirilebilir mi? Hukukta hiçbir şeyin kolay olmadığını biliyoruz.

\footnotetext{
* Doç. Dr., Türk Alman Üniversitesi, Hukuk Fakültesi, Ceza Hukuku Anabilim Dall.

** Doç. Dr., Marmara Üniversitesi, Hukuk Fakültesi, Medeni Usul ve İcra-İflas Hukuku Anabilm Dalı.
} 


\section{I.Ceza Yargılaması'nda Değerlendirme Yasağının Özgürlük ve Emniyet Çatışması Bakımından İşlevi ve Anlamı}

"Her şeye rağmen illa maddi gerçeğin bulunması gerektiği, ceza yargılamasının bir ilkesi değildir"1.

Hukuk devleti ilkesini ve insan haklarını benimsemiş bir ceza adaleti her zaman ceza adaletinin işlevselliği ile şüphelinin temel hak ve özgürlükleri bakımından bir çatışma ilişkisindedir - bir nevi emniyet özgürlüğe karşı. Buradaki menfaat çatışmasının dengelenmesi gerekmektedir. Bu, ceza yargılaması ve ceza usul hukukunun bütünü için şart olduğu gibi, münferit kovuşturma işlemleri için de geçerlidir, örneğin evin aranması veya ses kaydının yapılması gibi. Liberal bir hukuk devletinde absolut / mutlak çözümlere yer yoktur. Söz ettiğimiz bu çatışma alanında ceza yargılamasındaki delilleri kullanma yasağı da yer almaktadır. Ceza adaletinin işlevselliği ise bu yasakla çatışma halindedir. Temel hak ve özgürlükler ile hukuk devleti ilkeleri ise bu yasağ 1 desteklemektedir. Yasağın uygulandığı hallerde liberal hukuk devleti, münferit olaylarda bir delilin incelenmesinden veya delil incelemesi sonucu elde edilen sonuçtan feragat etmekte ve böylece ceza adaletinin işlevselliğini azaltmaktadır. Bunu insan onuruna, insan haklarına ve hukuk devletine verdiği önemden dolayı yapmaktadır.

\section{Ceza Yargılaması'nda Delillerin Kullanılması Yasağı Alman Ceza Usul Kanunu'nda nihai olarak düzenlenmemiştir (örneğin: § I36a, I00d, I60a Abs. I Satz 2, 252 StPO)}

Alman Ceza Usul Kanunu sadece birkaç normda delillerin kullanılması yasağını düzenlemiştir. Biz burada sadece $\$ 136$ a Alman Ceza Usul Kanunu’nu vermek istiyoruz:

“(1) Şüpheliye eziyet ederek, yorulmasını sağlayarak, vücutsal bütünlügüne ihlallerde bulunarak, ilaç vererek, kötü muamele ederek, kandırarak ve hipnoz uygulayarak irade beyanı etkilenemez. Ancak ceza yargılamasının izin verdiği ölçüde zor kullanılabilir. Kanunda öngörülmemiş bir tedbir ile korkutmak veya kanunda öngörülmemiş bir faydanın vaat edilmesi yasaktır.

(3) Fıkra 1 ve fıkra 2'deki yasaklar üzerinde şüphelinin tasarruf yetkisi bulunmamaktadır. Anılan fıkralara aykırı şekilde elde edilen ifadeler, şüpheli izin icazet etse dahi, kullanılamaz.”.

Anılan madde 1950'de kanuna girmiştir ve Almanya'daki nasyonal sosyalist tarihi dikkate alınarak düzenlenmiştir. Kanundaki ve insan hakları dayanağı ise Alman Anayasa'sının 1. Maddesidir: "İnsan onuru asla ihlal edilemez."

1 BGHSt. 14, 358, 365. 
Kanunda düzenlenmiş bu hükümlerin tahdidi olmadığı kabul edilmektedir². Bundan dolayı da içtihatlarda ve doktrinde ceza yargılama hukukundaki delilleri kullanma yasağı hususunda görüşler geliştirildi.

\section{Ceza Yargılaması'nın Her İhlali Bir Kullanma Yasağı ile Neticelenmiyor3. İhlal Nedeni ile Kullanma Yasağının Geçerli olup Olmadığı Hususu Alman Federal Mahkemesi'nin İçtihatlarına göre bir Değerlendirme Meselesidir.}

Hukuk devletinin ceza yargılamasına mutlak çözümler uymamaktadır. Hukuk Devleti’nde ceza adaletinin işlevselliği ile şüphelinin temel hak ve özgürlükleri arasında bir menfaat dengesinin sağlanması gerekmektedir. Bundan dolayı da içtihatlar pragmatik bir çözüm benimsemiş ve somut olayda değerlendirme yapılarak, delillerin kullanılmaması hususunda karar verilmesi gerektiğini ifade etmektedir. Peki bu bağlamda hangi hususlar değerlendirilecektir? İçtihatlara ${ }^{4}$ göre şu hususlar dikkate alınmalıdır: yargılama hukukundaki ihlalin ehemmiyeti; şüphelinin korunmaya değer hakları; işlenen fiilin ağırlığı; delilin acaba farazi olarak da olsa başka yoldan elde edilme ihtimalini bulunup bulunmadığı husus; delilin önemi. Federal Mahkeme’ye göre eğer ihlal edilen yargılama hukukuna ait norm, şüphelinin veya sanığın yargılamadaki pozisyonunu temelden koruyan bir norm ise, o zaman delillerin kullanılması yasağı söz konusudur.

Bu bağlamda Federal Mahkeme’nin klasikleşmiş temel bir kararı bulunmaktadır. Bu karar $₫$ 136 Alman Ceza Usul Kanunu’na ilişkindir. BGHSt 38, 214: Şüpheliye, şüpheli olarak ifadesi alınırken $₫ 136$ kapsamında hakları söylenmemiştir. Söz konusu norma göre ceza yargılamasında susma hakkı ve bir savunma avukatı isteme hakkı bulunmaktadır. Şüphelinin bu her iki hakkı hukuk devletinin ceza yargılamasındaki temel prensiplerini, hatta çekirdek prensiplerini teşkil etmektedir. O halde şüphelinin ifadesi bakımından sonuç nedir? Ceza yargılamasında bu ifade kullanılabilecek midir? Cevap net ve menfaat değerlendirmesine bile gerek yoktur5: "Ceza yargılamasında kimsenin kendi aleyhinde ifade vermesine zorlanamaz, dolayısılla susma hakk1 vardır ve bu hak ceza yargılamasının kabul edilmiş bir ilkesidir. Bu ilkenin kabulü insan onuruna saygıdan doğmuştur. Şüphelinin kişisel haklarını korumaktadır ve dolayısıyla adil yargılanma hakkının vazgeçilmez bir gereksinimidir.".

Alman Federal Mahkemesi de şöyle karar vermiştir (BGHSt 38, 214):

“1. Şüphelinin ifadesi alınmadan önce polis memuru kendisine yöneltilen suç bakımından susma hakkının bulunduğunda dair bilgilendirme yapılmamış olması halinde, şüphelinin verdiği ifade kullanılamaz.

BGHSt 38, 214.

Bak. OLG Düsseldorf, NStZ 2017, 177; Beulke, Strafprozessrecht, 13. Bas1, 2016, kenar notu 457; Heghmanns, ZfS 2016, 404 yazar burada yeni bir konept arayışı içindedir.

4 BGHSt 38, 214; BGHSt 53, 112.

5 Bak. BGHSt 38, 214. 
2. Ancak şüpheli, bilgilendirme yapılmamış olsa bile, susma hakkına vakıf ise, o zaman delili kullanma yasağı devreye girmemektedir. Aynısı, sanı̆̆ın duruşmada, kendisinin bilgilendirilmeden verdiği ifadesinin kullanılmasına icazet vermesi veya $₫ 257$ 'de anılan kesite kadar buna itiraz etmemesi hali için de geçerlidir. ...”.

Alman Federal Mahkemesi’nin bu kararı doğru bir sonuca varsa dahi, menfaat değerlendirmesi belirsiz ve somut olaylarda öngörülebilir değildir ${ }^{6}$. Oysa hukuk devleti netlik be hukuk güvenliği istemektedir.

Türk Anayasası'nın 38. Maddesinin 6. Fıkrasında da "Kanuna aykırı olarak elde edilmiş bulgular, delil olarak kabul edilemez." diye ifade etmektedir.

\section{Alman Federal Mahkemesi'ne göre Ceza Yargılaması'nda Delil Kullanma Yasağı bir İstisnadır! İçtihatlara göre Kullanma Yasağı Ancak Keyfiyet veya Bilinçli İhlallerde Söz Konusu Olmaktadır. Bu Bağlamda Dar bir Kriter Söz Konusudur.}

Uygulamada, kullanma yasağının kabulü temkinli kabul edilmektedir ${ }^{7}$, zira Alman Federal Mahkeme’ye göre ${ }^{8}$ : "Delilin kullanılması yasağı, temel hak ve özgürlüklerin planlı veya sistematik şekilde ağır, bilinçli veya keyfi yargılama ihlalleri ile bertaraf edilmesi halinde mevcuttur.”.

Bu eleştirilere sebebiyet vermektedir. Ceza Usul Kanunu, hukuk devletinin ceza yargılamasını belirlemektedir. Ceza Usul Kanunu’nda şüpheliye karşı hangi işlemlerin yapılabileceği ve bunların şartlarını düzenlemektedir. Böylece şüphelinin haklarının ihlali, yani bireysel haklar ile kamu menfaati arasındaki çatışmayı düzenlemektedir, yani emniyet ve özgürlük arasındaki çatışmayı. Yargı organları, ceza adaletinin işlevselliği adına bu düzenlemeleri ihlal ederlerse, o zaman aslında ihlal edilen temel hak ve özgürlükler ile hukuk devleti anlayışı zaten delilin kullanılması yasağını desteklemektedir. Bu bağlamda ihlal edilen yargılama normunun korumak istediği menfaat önem kazanmaktadır - buna korunmak istenen menfaat öğretisi denilmektedir ${ }^{9}$. Yargılama normu ihlaline rağmen delilin kullanılması, bir hukuk devletinde kural olarak istisnai teşkil etmesi gerekmektedir, tersi olamaz - pro libertate (şüphe halinde özgürlükte yana olmak).

Bu kendini özellikle susma hakkında kendini göstermektedir. Susma hakkı ve kendi aleyhinde ifade vermeme hakkı (nemo-tenetur-se-ipsum-accusare-ilkesi), Avrupa İnsan Hakları Bildirgesi’nin 6. addesindeki adil yargılanmanın çekirdek konularıdır. Bu hakları devlet ne zorla ne de - ki bu husus içtihatlarda tartışmalıdır - şüpheliyi kandırarak ihlal edemez. Tebliğin başında verdiğimiz örnekte (BGHSt 34, 362) de bundan dolayı hali ile delillerin kullanılması yasağı söz konusu olacaktır.

\footnotetext{
6 Bak. Heghmanns, ZfS 2016, 404.

7 Bak. BGH NJW 2007, 2269; OLG Düsseldorf, NStZ 2017, 177; Heghmanns, ZfS 2016, 404.

8 BGH NJW 2017, 1332.

9 Bak. Beulke kenar notu 458.
} 


\section{Alman Anayasası'nın I.maddesine Göre Hayatın Yaşanmasına İlişkin İhlali Asla Mümkün Olmayan bir Çekirdek Alan Vardır}

Alman Federal Mahkemesi bu kurum ile hukuk tarihi yazmıştır. İnsan onurunu (ki bak. Alman Anayasası'nın 1. maddesi), bireylerin temel hak ve özgürlüklerini ve ceza yargılamasında sanıkların haklarını kuvvetlendirmiştir. Yargı organları ve polis hukuken ve fiilen bu çekirdek alana saygı göstermek zorundalar, ihlal edemezler. Bu konuda menfaat değerlendirilmesi yapılamaz $^{10}$. Bu alanda devletin zoru geçmemektedir.

Örnek (BGHSt 50, 206) ${ }^{11}$ : Sanık A, cinayetten ömür boyu hapis cezasına çarptırılmıştı. A, öldürdüğü kişi ile tartışmış ve tartışma esnasında bir odun parçası ile elinde onu tehdit etmiş ve "Seni daha sonra öldüreceğim" diye bağırmıştır. Gerçekten de kişi massiv ve köşeli bir cisim ile öldürülmüştür. Ancak cinayet aleti hiçbir zaman bulunamamıştır. Araştırmalar sonuçsuz kalmıştır. Yıllar sonra A bir iş kazası geçirmiştir. Ş kazası sebebiyle yapılan araştırmada polis A'nın evinde, zamanında cinayette kullanılan cinayet aleti olabilecek nitelikte bir odun parçasına rastlamıştır. Bunun üzerine polis, cinayete ilişkin tahkikatını yeniden başlatmış ve hakimin izni ile A’nın tedavi amaçlı bulunduğu hastanedeki odasına dinleme cihazı yerleştirmiştir. $\mathrm{Bu}$ bağlamda A bir telefon konuşması akabinde kendi kendine konuşmuştur ve bu konuşması da kaydedilmiştir. Konuşma şu şekildeydi: "Çok agresif, çok agresif, çok agresif! Kafasından vurmalıydım onu, kafasından vurmalıydım onu, kendi öldü.”. Mahkeme bu sözlerden, sanığın, şüpheyi kendi üzerinden uzaklaştıran başka bir öldürme şekline ilişkin düşüncelerde bulunduğu sonucuna varmıştır.

Hayata ait çekirdek alan nedir? Kendi kendine yapılan bir konuşma buna dahil midir? İçerik itibarı ile şüpheliyi zan altında bırakacak olan bir kendi kendine yapılan konuşma, ceza yargılamasında sanığa karşı kullanılabilir mi?

Haydi oylama yapalım!

İnsanın birey olarak kendi hakimiyetine ait bir özel yaşam alanı olmalıdır; bu yaşam alanında birey kendi düşünceleri ve işlemleri ile başbaşa olabilmelidir. İnsan onuruna uygun ve özgür bir yaşamda, sosyal olan insanın bu tür bir yaşam alanı olmalıdır ve bu yaşam alanına devlet girememelidir. Şeklen düşünecek olursak bu herkesin konutudur. Alman Anayasası’nın 13. maddesinde korunmuştur ki, her birey evinde özel yaşam alanı bulabilsin. Ancak konuta ilişkin koruma mutlak değildir. Ayrıca düşüncelerin, sözcüklerin ve işlemlerin acaba ihlali mümkün olmayan insan onuruna dahil midir: "Şüpheli kendi kendine konuşarak şüphesiz olarak gizli kalmasını istediği bir hususta fikirlerini beyan etmektedir. ... Kendi kendine konuşma, bireyin bilinci ile ilgilidir ve ister istemez ortaya çıkarak, kişisel beklentileri, korkuları, değerlendirmeleri, kendine talimatları ve manevi fiziksel duyguları içermektedir. Buna göre kendi kendine konuşma bireysel karakterlidir ve doğrudan başkalarını veya toplumu etkilemez." ${ }^{2}$.

10 Bak. Heghmanns, ZfS 2016, 404, 411.

11 Bunun için Jahn, StraFo 2011, 117 - çok iyi bir makale; bak ayrıca Valerius, JA 2006, 15.

12 Bak. BGHSt 50, 206. 
Alman Anayasası'nın 1. maddesindeki insan onurunun ihlali hiçbir menfaat değerlendirmesine dahi tabi tutulmadan delilin kullanılması yasağına tabidir ${ }^{13}$.

\section{Kural Olarak Ceza Yargılaması'ndaki Delili Kullanma Yasağının Uzayan bir Etkisi Bulunmamaktadır}

Başlı başına başka bir konu ise, delili kullanma yasağının kapsamıdır. Bu yasağın uzayan bir etkisi var mıdır? Bu her hukuk düzeninde sorulan bir sorudur. Alman Ceza Usul Kanunu'nun $\$ 136$ ya göre yapılmayan bilgilendirme sonucunda şüpheli, işbirliği içerisinde bulunduğu başka şüphelilerin isimlerini vermiştir ve hatta çalınan malların yerini söylemiştir. Hakikaten söz konusu yerde de olaya ait izler bulunmaktadır. Bunların kullanılması mümkün müdür, zira aslında şüphelinin ifadesi kullanılamaz. Alman Federal Mahkemesi’nin ${ }^{14}$ çözümünü sanırım tahmin ediyorsunuzdur: "Federal Mahkeme’nin daha öncede kararlaştırdığı üzere, yapılan bir yargılama hatası sonucu ortaya çıkan delili kullanma yasağı doğrudan bütün ceza yargılamasının etkilenmesine sebebiyet vermemelidir. Bir tanı̆̆ın duruşmada verdiği ifadesi, ... yargı organlarının aynı tanığı daha önce şüpheli olarak atfedip, şüphelinin ifadesini alırken ona susma hakkı hakkında bilgi vermemiş olmaları rağmen, şüphelinin ifadesi ile ortaya çıkan başka olguların kullanılması mümkündür. Kullanma yasağının bu şekilde sınırlandırılması zaten işlevsel bir ceza adaleti bakımından söz konusu olamayacağı gibi, ayrıca elzemdir, zira polisin farazi olarak söz konusu tanık olmadan da, yani ihlal yapılmadan da aynı sonuca varma ihtimalinin olup olmadığı da hiçbir zaman net bir şekilde tespit edilemeyecektir.”

Ama: Bu çok yüzeysel. Ceza yargılamasının etkilenmesi - eğer başka “temiz” deliller varsa - söz konusu olmayacaktır ve sanık yargılanabilecektir. Yasağın uzağa etkisi hakkında yüzeysel karar verilmesi, yargı organlarının yargılama normlarını ihlal etmeye davet gibi olacaktır. Dolayısıla en azından ağır hatalarda, ki bunlar örneğin insan onurunu ihlal etmiş olabilir veya şüphelinin yargılamadaki temel haklarına ilişkin bir ihlal mevcutsa, yasağın uzağa etkisi kabul edilmelidir. Aynısı Alman Ceza Usul Kanunu’nun $\$ 136$ a maddesi ${ }^{15}$ için de geçerlidir.

\section{Sonuç}

Mutlak bir güvenlik yoktur. Mutlak bir özgürlük de yoktur. Ceza hukukunda güvenlik ile özgürlük arasındaki çatışma hem soyut olarak hem de şüpheliye karşı alınan tedbirlerle somut olarak kendini göstermektedir. Liberal hukuk devleti insanın onurunu korumak zorundadır ve bu bağlamda bir denge bulmak zorundadır. Ceza yargılamasında delillerin kullanılması yasağı bunun bir görünümüdür. Özgürlügü temin etmekte ve hukuk devletini sağlamlaştırmaktadır.

13 Bak. Jahn, StraFo 2011, 117.

14 Bak. BGHSt 34, 362.

15 Bak. Beulke kenar notu 482 vd.. 